\title{
Recordando a nuestra querida Vicki Cassman desde el Valle de Azapa
}

\author{
Vivien G. Standen ${ }^{1}$
}

Recuerdo como si fuera hoy cuando nos visitó por primera vez Vicki Cassman a fines del otoño del año 1983, llena de vida, juventud y sueños, en el Museo San Miguel de Azapa de la Universidad de Tarapacá. $\mathrm{Su}$ visita se daba en el contexto de un programa de intercambio con la Universidad de Delaware para promover el registro, manejo y conservación de las colecciones depositadas en museos. Era también su primera visita a Sudamérica.

En esos años los temas patrimoniales y las acciones para el registro y la conservación de los abundantes vestigios arqueológicos del norte de Chile no estaban suficientemente implementadas ni desarrolladas. Aunque excepcionalmente en Arica, Liliana Ulloa ya había iniciado a comienzos de la década de los años 1970 su dedicación al estudio y la conservación de los textiles. Un rasgo particular de las colecciones en Arica es que incluían un alto número de cuerpos humanos momificados de forma natural. Recuerdo que una de las cosas que le impactó profundamente a Vicki, fue el modo en que se abordaba el estudio de esos cuerpos. En ese tiempo trabajaba en la Universidad de Tarapacá el doctor Marvin Allison para desarrollar un programa de investigación en estudios paleopatológicos de las poblaciones prehispánicas. Para ello se realizaban autopsias a los cuerpos. Desde la perspectiva actual estos serían procedimientos totalmente inaceptables, sin embargo, hay que precisar que en aquella época eran los habituales que se empleaban. Recuerdo que Vicki siempre se opuso tenazmente a la forma en que se abordaban este tipo de estudios y siempre dio una voz de alerta.

En los años posteriores, Vicki colaboró en forma permanente con nuestro museo con miras a mejorar las condiciones de preservación y almacenaje de las colecciones, aportando su conocimiento, experiencia y profesionalismo en estos temas. Siempre trabajó en forma laboriosa y eficiente, sin ninguna estridencia. En esos tiempos de pobreza de nuestro Museo, Vicki en cada viaje a Chile traía materiales de conservación desde USA (recuerdo con especial cariño los pliegos de papel sin ácido para envolver los materiales).

En lo personal, Vicki fue siempre una persona generosa, afable y muy optimista frente a la vida. Estuvo continuamente al lado de los más débiles y necesitados, buscando donde poder contribuir para tener una mejor convivencia y una mejor sociedad humana. Sus últimas cruzadas estaban alineadas en la lucha contra la contaminación del medio ambiente y en lo político, hasta que tuvo fuerzas participó activamente en cada meeting contra Donald Trump. Su última lucha, que penosamente no pudo ganar fue en contra de su enfermedad. Si bien su cuerpo partió, su presencia, el recuerdo de su vida y su paso por nuestro museo, estarán siempre presente en nuestra memoria.

\footnotetext{
${ }^{1}$ Departamento de Antropología, Universidad de Tarapacá, Arica, Chile.
} 